\title{
FONTES COMPLEMENTARES DE FINANCIAMENTO EM INSTITUIÇÕES PÚBLICAS NÃO FEDERAIS DE ENSINO SUPERIOR (IPES): ANẤLISE SOBRE A GESTÃO DE CONVÊNIOS FEDERAIS EM UMA UNIVERSIDADE MULTICAMPI
}

\author{
COMPLEMENTARY SOURCES OF FINANCING IN NON-FEDERAL PUBLIC \\ INSTITUTIONS OF HIGHER EDUCATION: ANALYSIS ON THE MANAGEMENT OF \\ FEDERAL AGREEMENTS IN A MULTICAMPI UNIVERSITY
}

Sergio Henrique Conceição

Doutor em Educação e Contemporaneidade Universidade do Estado da Bahia - UNEB

Camaçari, Bahia - Brasil shconceicao@uneb.br

(iD Cristiane Neves de Oliveira Mestra em Gestão e Tecnologias Aplicadas à Educação Universidade do Estado da Bahia - UNEB

Salvador, Bahia - Brasil cnoliveira@uneb.br

\begin{abstract}
Resumo: Este trabalho, a partir da compreensão da relevância do papel das instituições públicas não federais de educação superior (IPES) na oferta de ensino, pesquisa e extensão, e a demanda por identificação de fontes complementares de financiamento às suas atividades, tem como objetivo identificar os fatores relevantes do processo de execução financeira de convênios celebrados entre a Universidade do Estado da Bahia (UNEB) e instâncias federais, no período de 2009 a 2014, provenientes do papel supletivo da União, enquanto fontes complementares de financiamento. Os resultados do estudo a partir de uma abordagem quantitativa, lastreado na técnica estatística da análise fatorial, indicaram as dimensões acadêmicas e espaciais, demarcados no contexto da multicampia universitária, como relevantes ao processo de execução financeira dos convênios federais em patamar satisfatório, sinalizando à gestão universitária possíveis encaminhamentos voltados ao aperfeiçoamento das práticas de gestão desses instrumentos.
\end{abstract}

Palavras-chave: assistência financeira; execução de convênios; gestão universitária.

Abstract: This work, based on the understanding of the relevance of the role of state universities in the provision of teaching, research and extension, and the demand for identification of complementary sources of financing for their activities, aims to present, in an exploratory way, the management theme of covenants with financial resources, from the complementary role of the Union, as supplementary sources of funding, within the framework of the State University of Bahia (UNEB), from 2009 to 2014. The results of the study from a quantitative approach, based on the statistical technique of factor analysis, indicated the academic and spatial dimensions, demarcated in the context of the university multicamp, as relevant to the process of financial execution of federal agreements at a satisfactory level, signaling the management possible referrals aimed at improving the practices of these instruments.

Keywords: financial assistance; execution of agreements; university management.

Para citar - (ABNT NBR 6023:2018)

CONCEIÇÃO, Sergio Henrique; OLIVEIRA, Cristiane Neves de. Fontes complementares de financiamento em instituições públicas não federais de ensino superior (IPES): análise sobre a gestão de convênios federais em uma universidade multicampi. Eccos - Revista Científica, São Paulo, n. 58, p. 1-22, e11404, jul./set. 2021. Disponível em: https://doi.org/10.5585/eccos.n58.11404. 


\section{Introdução}

A dinâmica organizacional de uma instituição pública não federal de educação superior (IPES), com configuração multicampi e multirregional, exige da gestão universitária uma contínua reavaliação de suas práticas institucionais, de forma a garantir com efetividade o cumprimento das responsabilidades constitucionais e regimentais, expressas nas ações finalísticas de ensino, pesquisa e extensão em todos os campi, preservando a transparência, a responsabilidade e a eficiência na gestão dos gastos públicos.

Considerando que essa configuração possui como função social precípua expandir a oferta de educação superior pública, gratuita e de qualidade, assim como contribuir para o desenvolvimento econômico social e local, a Universidade do Estado da Bahia (UNEB), lócus deste estudo, tem se consolidado como uma instituição relevante no processo de desenvolvimento do estado da Bahia (BARBOSA, 2013).

Nesse cenário, reveste-se de especial importância a gestão das transferências voluntárias, formalizadas por meio de convênios celebrados com órgão federais, cuja captação tem se constituído em um caminho alternativo à sustentação econômica dessa IPES, diante do frequente contingenciamento de recursos vinculados do Tesouro estadual (MOTA JÚNIOR; CONCEIÇÃO, 2020).

Dessa forma, considerando a complexa estrutura organizacional e a dispersão geográfica que caracterizam essa universidade, multicampi e multirregional, bem como as falhas eventualmente identificadas na execução de convênios, e visando ao contínuo aprimoramento dos procedimentos de organização e gestão administrativa e financeira (BOAVENTURA, 2009), o presente trabalho busca identificar quais os fatores relevantes do processo de execução financeira de convênios celebrados entre a Universidade do Estado da Bahia (UNEB) e instâncias federais, no período de 2009 a 2014. Para alcance desse propósito, o estudo organiza uma metodologia de natureza bibliográfica e documental de abordagem quantitativa.

O trabalho está organizado em cinco seções: nesta primeira seção introdutória, apresentam-se o tema e os objetivos da pesquisa. Em seguida, na seção de referencial teórico, são expostos os pressupostos teóricos da compreensão da gestão e financiamento da atividade universitária. Logo após, na terceira seção, evidenciamos a metodologia desenvolvida na pesquisa, e, subsequentemente, a quarta seção apresenta os resultados obtidos no estudo. Por fim, na quinta seção, são tecidas as considerações e recomendações finais da pesquisa. 


\section{Referencial teórico}

\subsection{A pesquisa sobre o financiamento da educação na educação superior}

A pesquisa acerca do financiamento da educação vem paulatinamente ampliando seu espaço no cenário das discussões da política educacional brasileira. $\mathrm{O}$ trabalho realizado por Cruz e Jacomini (2017) indicou maior ênfase dos estudos realizados na perspectiva da educação básica, nas relações de cooperação dos entes federativos e na constituição e evolução dos fundos constitucionais (Fundef-Fundeb). Os estudos relacionados ao financiamento da educação superior representaram $10 \%$ das pesquisas identificadas pelas autoras (CRUZ; JACOMINI, 2017).

No âmbito das pesquisas dedicadas especificamente ao financiamento da educação superior, pode-se estabelecer que estas se apresentam como estudos que investigam a caracterização e evolução histórica da política de financiamento da educação superior no Brasil, estudos que averíguam as experiências internacionais e seus impactos no cenário nacional, considerando o contexto do capitalismo globalizado, e estudos que avaliam a evolução dos investimentos na educação superior por segmentos públicos e privados da sociedade e sua repercussão na oferta (SGUISSARDI, 2005; CHAVES; AMARAL, 2016; AMARAL, 2008; CARVALHO, 2006).

No contexto dos estudos dedicados à caracterização e evolução da política nacional da educação superior, indica-se que, especialmente a partir da década de 1990, ocorre no Brasil um alinhamento tenaz e sistemático do movimento de implantação de uma lógica mercantil em que o Estado, a partir de uma premissa de suposta racionalidade fiscal, reduz os investimentos públicos nessa área, direcionando a política para uma ratificação do protagonismo da oferta privada de ensino superior, financiada por meio de recursos públicos direcionados às IES de natureza privada, a partir de programas baseados em renúncia fiscal (SAGUISSARDI, 2005; CORBUCCI, 2004; CUNHA, 2004).

Estudos que investigam o cenário do financiamento da educação superior em contexto mundial indicam que esse alinhamento na política educacional nacional, no âmbito da educação superior, ainda no contexto do capitalismo global, determina que a educação como um todo e, particularmente, a educação superior, deve ter caráter privado e particular (SANTOS; CHAVES, 2020).

Essas premissas são estabelecidas no âmbito do Banco Mundial, o qual enuncia, como principal agência disseminadora desse receituário, o pressuposto da incorporação dos 
mecanismos de financiamento privados, fornecidos por instituições financeiras a estudantes, que, por sua vez, acessam, prioritariamente, educação paga, mesmo quando ofertada por instituições estatais, e, consequentemente, o fortalecimento da financeirização do capitalismo, constituindo nova vertente de fundos financeiros vinculados às carteiras de créditos das dívidas estudantis (MOTA, 2019; TRINDADE, 2004; LIMA, 2011).

Ainda na perspectiva dos estudos que contextualizam o conjunto mundial das políticas de financiamento da educação superior e suas repercussões no Brasil, as pesquisas evidenciam que, apesar do déficit de oferta pública, o país opta por aderir aos modelos majoritários nos países da OCDE e já assimilados na América Latina e Caribe, indicando que outras etapas dessa agenda neoliberal hegemônica reservam um papel meramente operacional, neoprofissional, heterônoma e empresarial/competitiva às instituições de educação superior (AMARAL, 2016; SEGRERA, 2016; DONOSO, 2008).

Por fim, os estudos que investigam o investimento público na educação superior indicam como última etapa para a instalação integral de um regime de pleno mercado, sugerido pelo capitalismo global e suas novas estratégias de acumulação, o processo de redução do investimento público da educação superior, notadamente dos investimentos diretos nas IPES. Como consequência, evidencia-se a precarização nas condições de oferta nessas instituições, repercutindo na valorização dos profissionais da educação e na manutenção e expansão de suas atividades e, sobretudo, sugerindo uma pretensa superação dessas limitações por meio da busca por recursos próprios para seu financiamento (SILVA, 2019; VELLOSO; MARQUES, 2005).

\subsection{A Universidade do Estado da Bahia (UNEB) e o contexto do financiamento da educação superior}

A partir de 1960, em virtude do intenso desenvolvimento do país, e para que fosse possível atender à crescente demanda por profissionais habilitados para o exercício da docência no sistema de ensino público estadual na Bahia, surgiu a necessidade de criar escolas de educação superior para formação de professores no interior do estado (BOAVENTURA, 2009).

Como corolário da junção dessas escolas de formação de professores, foram sendo estruturadas as Universidades Estaduais Baianas, com vistas a contribuir para o processo de desenvolvimento regional.

Nesse contexto, surgiu a Universidade do Estado da Bahia (UNEB), vinda da reorganização do Centro de Educação Técnica da Bahia (CETEBA), o qual foi autorizado a funcionar mediante convênio entre o Ministério da Educação e Cultura (MEC) e o Governo do Estado da Bahia, por meio da Portaria Ministerial n ${ }^{\circ}$. 111, de 19 de fevereiro de 1968 . O 
CETEBA foi transformado em Fundação em 10 de abril de 1974, e assim funcionou até o advento da Lei Delegada $n^{\circ}$. 12, de 03 de dezembro de 1980, por meio da qual foi criada a Superintendência de Ensino Superior do Estado da Bahia (SESEB), com status de autarquia estadual, vinculada à Secretaria de Educação e Cultura do Estado da Bahia (SEC) (UNEB, 2015b).

Constituídas ao longo do país para suprir fundamentalmente a ausência histórica da oferta de ensino superior federal, especialmente no interior do país, as instituições públicas não federais de educação superior (IPES) se tornaram um encargo assumido pelos estados, pautados a responder pela omissão federal.

No Brasil, o financiamento das IPES está vinculado à Administração Pública Estadual, conforme estabelecido no art. 211, § $1^{\circ}$, caput, da Constituição Federal de 1988 (BRASIL, 1988), sendo a atuação da União feita por meio da assistência técnica e financeira aos entes federados.

Percebe-se, nesse contexto legal, a inexistência de normas suficientemente regulamentadas para o financiamento do ensino superior sob responsabilidade dos entes federativos não federais. Note-se, ainda, que existem lacunas na articulação federativa, no campo da educação superior, se for considerado que na assistência voluntária inexistem normas específicas, bem como a não efetivação do sistema nacional de educação.

No que lhe compete, a Constituição do Estado da Bahia (CE/BA) (BAHIA, 1989) assegura que o ensino superior é responsabilidade do Estado, e será ministrado pelas Instituições Estaduais do Ensino Superior, mantidas integralmente pelo Estado (BAHIA, 1989, art. 262, caput).

Segundo Barbosa (2013, p. 70-71), predomina no financiamento do ensino superior da Bahia o modelo incremental. De acordo com Velloso (2000, p. 48), um orçamento incremental ocorre quando a definição dos montantes de recursos a serem alocados para os programas, ações, órgãos ou despesas se realiza mediante incorporação de acréscimos marginais em cada item de despesa, mantendo-se o mesmo conjunto de despesas do orçamento anterior (ou com pequenos ajustes). Desta forma, as opções e prioridades estabelecidas no passado tendem a permanecer inalteradas ao longo do tempo, e o orçamento termina não refletindo uma reavaliação quanto a novas necessidades e prioridades da sociedade (OLIVEIRA, 2017).

Apesar do crescimento em termos nominais, o investimento estadual na instituição não equaciona de forma suficiente em face da demanda, tanto para a manutenção quanto para a elevação dos padrões acadêmicos e institucionais. Nesse contexto, torna-se bastante relevante a assistência financeira da União, mais comumente formalizada por meio de convênios, como 
forma de garantir equalização de oportunidades e padrão mínimo de qualidade do ensino (BRASIL, 1988, art. 211, § $1^{\circ}$, caput).

Na tipologia de assistência financeira da União à educação, encontra-se a seguinte diferenciação: a assistência compulsória e a voluntária. A primeira, chamada oficialmente de constitucional legal, diz respeito a ações inscritas na Constituição da República ou na legislação, por exemplo, a complementação da União ao Fundo de Manutenção e Desenvolvimento de Educação Básica e de Valorização dos Profissionais da Educação (FUNDEB). A assistência voluntária compreende ações não prescritas na legislação, as quais, na atualidade, são muitas e variadas, desde, por exemplo, programas de formação inicial ou continuada de profissionais da educação a repasses de recursos para a construção de escolas (FARENZENA, 2012, p.108).

De acordo com a Lei de Responsabilidade Fiscal (LRF) - Lei Complementar $n^{\circ}$. 101/2000 -, em seu artigo 25, transferência voluntária é “[...] a entrega de recursos correntes ou de capital a outro ente da Federação, a título de cooperação, auxílio ou assistência financeira, que não decorra de determinação constitucional, legal ou os destinados ao Sistema Único de Saúde" (BRASIL, 2000, art. 25, caput).

Sendo o entendimento de natureza voluntária, as transferências de recursos financeiros da União para as IPES, formalizadas mais comumente mediante convênios, ocorrem normalmente em decorrência da aprovação de projetos dessas instituições, em editais e programas especiais de apoio à capacitação, expansão e modernização da infraestrutura, projetos de extensão, entre outros, ou por intermédio de emendas parlamentares do Congresso Nacional (OLIVEIRA, 2017).

Com o advento do Sistema Federal de Convênios (SICONV), o chamamento público passou a ser divulgado também por meio desse sistema, conforme preceitua o artigo $8^{\circ}$, da Portaria Interministerial no. 424/2016 (BRASIL, 2016).

Nesse contexto, encontram-se elencados no Quadro 1 os principais financiadores da educação superior e suas respectivas áreas de apoio: 
Quadro 1 - Principais órgãos federais financiadores da educação superior

\begin{tabular}{|l|l|}
\hline \hline ÓRGÃO & ÁREA DE APOIO \\
\hline Financiadora de Estudos e Projetos - FINEP & Apoio a Projetos de Desenvolvimento Tecnológico \\
\hline $\begin{array}{l}\text { Fundação da Coordenação de Aperfeiçoamento de } \\
\text { Pessoal de Nível Superior - CAPES }\end{array}$ & $\begin{array}{l}\text { Investimentos na formação de pessoal no país e } \\
\text { exterior }\end{array}$ \\
\hline $\begin{array}{l}\text { Fundo Nacional de Desenvolvimento Educacional - } \\
\text { MEC/FNDE }\end{array}$ & $\begin{array}{l}\text { Implementação de Políticas de Educação Superior a } \\
\text { nível nacional }\end{array}$ \\
\hline Secretaria de Educação Superior - MEC/SESU & $\begin{array}{l}\text { Apoio à formação de pessoal e implementação de } \\
\text { Política Nacional de Educação Superior }\end{array}$ \\
\hline
\end{tabular}

Fonte: Pesquisa própria (OLIVEIRA, 2017).

As fontes complementares da União direcionadas às IPES, apesar de positivas, parecem camuflar a ausência de atuação mais efetiva desse ente federal em seu papel supletivo constitucional, para a garantia do direito à educação pública de qualidade.

É possível refletir, em caráter mais amplo, que o processo relacionado aos limites e dificuldades vivenciados no financiamento e manutenção da UNEB, assim como as demais IPES, insere-se em um cenário amplo do capitalismo global, que agenda a educação superior, preliminarmente, à precarização e à impossibilidade de ampliação das atividades, ainda que sinalizadas pelas metas de taxa de matrícula para educação superior pública nos planos nacionais de educação e, complementarmente, fomenta a expansão do financiamento público direcionado a instituições privadas mediante programas como FIES e PROUNI. Finaliza com a configuração de um mercado financeiro de financiamento para matrículas em instituições privadas (OLIVEIRA, 2017).

Todos esses elementos postos ratificam um cenário de redução do papel do Estado nas políticas direcionadas à educação superior, ampliação da mercantilização e financeirização, reduzindo, inclusive, o papel estratégico da educação superior no acesso ao desenvolvimento social e tecnológico nos países emergentes, relegando tanto as IPES quanto as instituições federais de educação superior (IFES) a uma dimensão meramente operativa e instrumental, dentro dos quadros do capitalismo global (AMARAL, 2016).

\section{Metodologia}

O estudo ora apresentado fundamentou-se na interlocução com a realidade da gestão universitária na Universidade do Estado da Bahia (UNEB) a partir do levantamento de questões e dados acerca da gestão de convênios com recursos federais no sentido de identificar aspectos relevantes para a execução satisfatória dos recursos captados a partir desses instrumentos, buscando identificar pontos de aperfeiçoamento de suas práticas (OLIVEIRA, 2017). 
No que se refere à natureza do estudo, trata-se de uma pesquisa exploratória, que busca identificar o montante transferido por órgãos federais para a UNEB, mediante convênios, no período de 2009 a 2014, e o comportamento da execução desses recursos. Caracteriza-se como exploratória, também, por ser uma pesquisa realizada no local onde o fenômeno ocorre, ou seja, dentro da universidade, a qual dispõe dos dados a serem coletados para explicar as incidências.

Quanto ao delineamento, de forma geral, tanto a pesquisa documental como a bibliográfica foram utilizadas, a fim de melhor se compreender o contexto das práticas de gestão relacionadas à execução dos convênios federais (OLIVEIRA, 2017).

A pesquisa segue a abordagem quantitativa, com a adoção da técnica estatística denominada regressão logística. Essa técnica caracteriza-se como uma análise multivariada de dados, que utiliza o procedimento de transformação logística aplicada à variável dependente (OLIVEIRA, 2017).

Segundo Hair Jr. et al. (2005), a regressão logística representa uma ferramenta de potencial ligeiramente superior às outras análises multivariadas por três aspectos básicos: (i) não é necessária a suposição de normalidade da amostra; (ii) trata-se de uma técnica mais robusta, dada a maior amplitude de aplicação; e (iii) possui característica similar à regressão linear múltipla.

O procedimento que calcula o coeficiente logístico compara a probabilidade de o evento ocorrer com a probabilidade de não ocorrer, sendo essa razão expressa da seguinte forma:

$$
\frac{\text { Prob (evento ocorrer) }}{\text { Prob (evento não ocorrer) }} \mathrm{P}(\mathrm{y}=1)=-\frac{1}{1+\mathrm{e} z} .
$$

Em que: $\mathrm{Z}=\mathrm{B} 0+\mathrm{B} 1 \mathrm{X} 1+\ldots+\mathrm{BnXn}$

Se a probabilidade prevista for maior que 0,50, então a previsão será sim; caso contrário, será não.

De acordo com Hair Jr. et al. (2005), os coeficientes da expressão representam medidas das variações de probabilidades chamadas razão de desigualdade, sendo expressos em logaritmos, precisando ser transformados de volta por meio do antilogaritmo, o que faz com que o efeito relativo às suas probabilidades seja avaliado de forma mais fácil. Para realizar o processo de estimação dos coeficientes, a regressão logística utiliza o procedimento de maximizar a "verossimilhança" de que um determinado evento ocorra. O modelo baseado em regressão logística estará tão bem ajustado quanto menor for a medida de -2LL (expressão que 
indica a verossimilhança), e melhor será o desempenho da regressão, sendo que o menor valor para -2LL é zero.

Na avaliação da regressão logística estimada existem diversos indicadores do "tipo R2", que, para a regressão logística, são denominados "pseudo R2", sendo que os softwares estatísticos geralmente evidenciam dois deles, o "R2 de Cox e Snell" e o "R2 de Nagelkerke". O processo de interpretação dos indicadores “pseudo R2” é semelhante ao indicador R2 das regressões lineares; quanto mais próximo de 1,0, maior o poder preditivo da regressão calculada (CONCEIÇÃO; PEREIRA, 2006).

Para a pesquisa bibliográfica, com o objetivo de melhor compreender o universo da gestão de convênios, foi realizada uma revisão do campo teórico acerca do financiamento da educação superior e da assistência financeira complementar da União.

Para a pesquisa documental, foram levantados dados institucionais que ainda não haviam recebido tratamento analítico, por meio de informações provenientes do Portal da Transparência do Governo Federal, de acesso público; Portal de Convênios (SICONV), acesso mediante senha; e dados fornecidos pela Secretaria de Contabilidade e Finanças da UNEB, inerentes às prestações de contas encaminhadas aos órgãos concedentes (OLIVEIRA, 2017).

A utilização de 3 (três) fontes de coleta de dados na investigação permitiu a obtenção de informações amplas e múltiplos dados necessários para a construção de um painel de dados que possibilitasse a análise quantitativa do fenômeno da execução financeira dos convênios.

Com base no levantamento de dados, que compreendeu a execução de 53 convênios com instâncias federais celebrados pela UNEB, no período de 2009 a 2014, foi realizada a segregação da amostra em 2 grupos distintos:

\section{(1) convênios com execução satisfatória e}

\section{(2) convênios com execução insatisfatória.}

O corte da amostra e sua consequente segregação ocorreram de forma discricionária no estudo. Foram considerados satisfatórios aqueles convênios com execução orçamentária/financeira $25 \%$ acima da metade dos recursos transferidos, ou seja, $75 \%$ de execução. A amostra formada pelo conjunto dos 53 convênios apresentou 19 convênios com execução orçamentária/financeira satisfatória e 34 convênios com execução orçamentária/financeira insatisfatória, ou seja, 19 convênios conseguiram executar os recursos captados em uma proporção superior a $75 \%$ dos valores recebidos, enquanto outros 34 convênios executaram menos de $75 \%$ dos recursos previstos nos convênios celebrados (OLIVEIRA, 2017). 
O trabalho assume as categorias de análise preconizadas para o contexto da gestão universitária multicampi prevista na literatura de Fialho (2005). São consideradas pela autora as dimensões acadêmicas, organizacionais e espaciais como estruturantes ao processo de atuação, organização e gestão de instituições de ensino superior multicampi.

A pesquisa então, a partir do painel de dados levantados acerca dos convênios federais, determinou em caráter discricionário 7 (sete) variáveis para cada dimensão categórica (acadêmica, organizacional e especial), capazes de, possivelmente, contribuir para o entendimento dos aspectos relacionados ao processo de gestão e execução desses instrumentos de financiamento (OLIVEIRA, 2017).

Na dimensão organizacional, o estudo tomou as variáveis Órgão Concedente (ACONC), Ação Governamental (AGOV) e Vigência da Execução (VG). Na dimensão acadêmica, a variável Ação Orçamentária (AORC), e na dimensão espacial, as variáveis Abrangência do Convênio (ABRAN), Unidade Institucional Responsável pela Gestão do Convênio (UIRGC) e Unidade Gestora de Execução Orçamentária e Financeira (UGEOF), conforme Quadro 2.

Quadro 2 - Variáveis independentes do estudo

\begin{tabular}{|c|l|c|}
\hline Variável & Descrição & Dimensão categórica \\
\hline $\mathrm{X}_{1}$ & Órgão concedente (ACONC) & Organizacional \\
\hline $\mathrm{X}_{2}$ & Ação governamental (AGOV) & Organizacional \\
\hline $\mathrm{X}_{3}$ & Ação orçamentária (AORC) & Acadêmica \\
\hline $\mathrm{X}_{4}$ & Abrangência do convênio (ABRAN) & Espacial \\
\hline $\mathrm{X}_{5}$ & Unidade institucional responsável pela gestão do convênio (UIRGC) & Espacial \\
\hline $\mathrm{X}_{6}$ & Unidade gestora de execução orçamentária e financeira (UGEOF) & Espacial \\
\hline $\mathrm{X}_{7}$ & Vigência de execução (VG) & Organizacional \\
\hline
\end{tabular}

Fonte: Elaboração da pesquisa (OLIVEIRA, 2017).

O painel de dados obtidos, a partir do levantamento realizado envolvendo os 53 (cinquenta e três) convênios celebrados com instâncias federais de fomento pela universidade, foi transformado em um painel de classificação "dummy", que considerava cada um dos itens das variáveis em suas dimensões organizacionais, acadêmicas e espaciais. Para esse painel de dados, foi aplicada a análise multivariada de dados logística com a utilização do software estatístico Statistical Package for the Social Sciences (SPSS), tendo sido identificados os resultados a seguir. 


\section{Resultados obtidos}

O programa SPSS, preliminarmente, possibilitou uma análise descritiva dos dados relacionados a cada uma das variáveis propostas no presente estudo, que já sinalizam importantes elementos para identificação dos fatores relevantes à execução financeira dos convênios celebrados com instâncias federais no âmbito da Universidade do Estado da Bahia (UNEB) no período de 2009 a 2014.

Para a variável Órgão Concedente (ACONC) foi identificado que 75,5\% dos recursos recebidos pela UNEB, no período em análise, tinham sido provenientes do Ministério da Educação e órgãos vinculados, e $24,5 \%$ oriundos de outros órgãos federais. Identificou-se, também, para essa variável, que, no geral, 64,2\% da execução foi classificada como não satisfatória, e apenas 35,8\% foi satisfatória (Tabela 1).

Tabela 1 - Variável Órgão Concedente (ACONC)

\begin{tabular}{l|c|c|c}
\hline \hline \multirow{2}{*}{ ACONC } & \multicolumn{2}{|c|}{ Execução Orçamentária/Financeira } & \multirow{2}{*}{ Total } \\
\cline { 2 - 3 } & $\begin{array}{c}\text { Execução } \\
\text { Satisfatória }\end{array}$ & $\begin{array}{c}\text { Execução Não } \\
\text { Satisfatória }\end{array}$ & \\
\hline Ministério da Educação & $15(28,3 \%)$ & $25(47,2 \%)$ & $40(75,5 \%)$ \\
\hline Outros & $4(7,5 \%)$ & $9(17,0 \%)$ & $13(24,5 \%)$ \\
\hline Total & $19(35,8 \%)$ & $34(64,2 \%)$ & $53(100,0 \%)$ \\
\hline \hline
\end{tabular}

Fonte: Elaboração da pesquisa (OLIVEIRA, 2017).

A variável Ação Governamental (AGOV) indica a natureza da transferência, se “Contemplação Nominal” (apoio a entidades de ensino superior não federais - emenda parlamentar) ou "Não Contemplação Explícita". Constatou-se que 83\% dos recursos transferidos foram provenientes de apresentação de projeto em atendimento a programas e editais de seleção, e que $17 \%$ vieram de emendas parlamentares, ou seja, apesar da existência da assistência financeira da União, o maior percentual destinado no período sob análise dependeu de seleção por mérito de projetos demandados pela própria instituição (Tabela 2).

Os dados evidenciaram também que dos 9 (nove) convênios provenientes de emendas parlamentares identificados, todos celebrados com o Ministério da Educação, por intermédio do Fundo Nacional de Desenvolvimento da Educação (FNDE), para apenas 4 (quatro) houve transferência dos recursos financeiros, fator que deve ser considerado na análise do percentual de execução orçamentária não satisfatória e na efetividade dessa ação governamental (Tabela 2).

Esse dado também sinaliza que, a despeito do esforço da ação parlamentar em destinar recursos complementares para o financiamento das IPES, essas iniciativas acabam reféns de contingenciamentos e outros trâmites que findam por frustrar tais iniciativas. 
Quanto aos convênios provenientes do mérito do projeto, houve uma execução orçamentária financeira satisfatória de $32,1 \%$ e não satisfatória de $51 \%$ (Tabela 2). Como já registrado, esse desempenho é bastante impactado pela não execução financeira dos recursos originários de emendas parlamentares.

Tabela 2 - Variável Ação Governamental (AGOV)

\begin{tabular}{|c|c|c|c|}
\hline \multirow[t]{2}{*}{ AGOV } & \multicolumn{2}{|c|}{ Execução Orçamentária/Financeira } & \multirow[t]{2}{*}{ Total } \\
\hline & $\begin{array}{c}\text { Execução } \\
\text { Satisfatória } \\
\end{array}$ & $\begin{array}{c}\text { Execução Não } \\
\text { Satisfatória }\end{array}$ & \\
\hline Contemplação Nominal (Emenda Parlamentar) & $2(3,8 \%)$ & $7(13,2 \%)$ & $9(17 \%)$ \\
\hline Não Contemplação (Mérito do Projeto) & $17(32,1 \%)$ & $27(51 \%)$ & $44(83 \%)$ \\
\hline Total & $19(35,8 \%)$ & $34(64,2 \%)$ & $53(100,0 \%)$ \\
\hline
\end{tabular}

Fonte: Elaboração da pesquisa (OLIVEIRA, 2017).

No que se refere à variável Classificação Orçamentária do Convênio (AORC), que está relacionada ao seu objeto, se ensino de graduação, pesquisa, extensão ou infraestrutura, o levantamento identificou que 23 (vinte e três) convênios foram relacionados à atividade de ensino, 6 (seis) à atividade de pesquisa, 16 (dezesseis) às atividades de extensão e 8 (oito) convênios relacionados com ações de melhoria de infraestrutura universitária (pavilhão de salas, laboratórios, equipamentos etc.) (Tabela 3).

Identificou-se, também, que tanto para os convênios que apresentaram um melhor desempenho em relação à execução orçamentária/financeira quanto para os que exibiram um desempenho insatisfatório, houve relacionamento com ações de ensino e extensão, e para os convênios de execução orçamentária/financeira insatisfatória, os convênios relacionados a infraestrutura também estão inseridos (Tabela 3).

Pode-se inferir, desse modo, que os processos licitatórios mais complexos à aquisição de itens de natureza permanente e investimentos, que caracterizam os convênios de infraestrutura, podem resultar em maiores dificuldades na execução financeira desses instrumentos específicos, afetando o cenário geral de execução financeira dos convênios federais (Tabela 3 ). 
Tabela 3 - Variável Classificação Orçamentária do Convênio (AORC)

\begin{tabular}{l|c|c|c}
\hline \hline \multirow{2}{*}{ AORC } & \multicolumn{2}{|c|}{ Execução Orçamentária/Financeira } & \multirow{2}{*}{ Total } \\
\cline { 2 - 3 } & Execução Satisfatória & Execução Não Satisfatória & \\
\hline Ensino & $13(24,5 \%)$ & $10(18,9 \%)$ & $23(43,4 \%)$ \\
\hline Pesquisa & $1(1,9 \%)$ & $5(9,4 \%)$ & $6(11,3 \%)$ \\
\hline Extensão & $4(7,5 \%)$ & $12(22,6 \%)$ & $16(30,2 \%)$ \\
\hline Infraestrutura & $1(1,9 \%)$ & $7(13,2 \%)$ & $8(15,1 \%)$ \\
\hline Total & $19(35,8 \%)$ & $34(64,2 \%)$ & $53(100,0 \%)$ \\
\hline \hline
\end{tabular}

Fonte: Elaboração da pesquisa (OLIVEIRA, 2017).

A variável Abrangência das Ações (ABRAN) revelou que 14 (quatorze) convênios celebrados com instâncias federais tinham abrangência departamental e que 39 (trinta e nove) deles tinham abrangência interdepartamental e/ou comunidade externa (Tabela 4).

Os resultados parecem sinalizar que o implemento de maior abrangência das ações, repercutem no maior número de unidades de atendimento envolvidas, podem representar em aumento na complexidade da gestão desses instrumentos, causando, possivelmente, dificuldades nas condições de execução financeira.

Tabela 4 - Variável Abrangência das Ações (ABRAN)

\begin{tabular}{l|c|c|c}
\hline \hline \multirow{2}{*}{ ABRAN } & \multicolumn{2}{|c|}{ Execução Orçamentária/Financeira } & \multirow{2}{*}{ Total } \\
\cline { 2 - 3 } & Execução Satisfatória & Execução Não Satisfatória & \\
\hline Departamental & $8(15,1 \%)$ & $6(11,3 \%)$ & $14(26,4 \%)$ \\
\hline Interdepartamental e Comunidade Externa & $11(20,8 \%)$ & $28(52,8 \%)$ & $39(73,6 \%)$ \\
\hline Total & $19(35,8 \%)$ & $34(64,2 \%)$ & $53100,0 \%)$ \\
\hline \hline
\end{tabular}

Fonte: Elaboração da pesquisa (OLIVEIRA, 2017).

A variável Unidade Responsável pela Gestão do Convênio (UIRGC) revelou que 42 (quarenta e dois) convênios foram geridos por órgãos da administração central universitária $(79,2 \%)$ e que 11 (onze) foram geridos por unidades departamentais (20,2\%), sinalizando claramente que o êxito da gestão dos convênios celebrados com instâncias federais não está relacionado ao local da gestão da iniciativa, ao contrário, tanto os convênios geridos por órgãos da administração quanto por unidades departamentais têm um déficit de desempenho da execução orçamentária/financeira, demonstrando que os fatores impactantes nesse processo manifestam-se indistintamente nos dois contextos (Tabela 5).

Tabela 5 - Variável Unidade Responsável pela Gestão do Convênio (UIRGC)

\begin{tabular}{l|c|c|c}
\hline \hline \multirow{2}{*}{ UIRGC } & \multicolumn{2}{|c|}{ Execução Orçamentária/Financeira } & \multirow{2}{*}{ Total } \\
\cline { 2 - 3 } & Execução Satisfatória & Execução Não Satisfatória & \\
\hline Administração Central & $15(28,3 \%)$ & $27(50,9 \%)$ & $42(79,2 \%)$ \\
\hline Departamento & $4(7,5 \%)$ & $7(13,2 \%)$ & $11(20,8 \%)$ \\
\hline Total & $19(35,8 \%)$ & $34(64,2 \%)$ & $53(100,0 \%)$ \\
\hline \hline
\end{tabular}

Fonte: Elaboração da pesquisa (OLIVEIRA, 2017). 
Para a variável Unidade Gestora Responsável pela Execução Orçamentária e Financeira (UGEOF), os resultados demonstraram 19 (dezenove) convênios com execução orçamentária/ financeira totalmente relacionada à administração central universitária e 34 (trinta e quatro) convênios com execução orçamentária/financeira descentralizada, subordinada às unidades departamentais, núcleos operacionais e Pró-Reitorias (Tabela 6).

Do mesmo modo que a variável anterior, a variável Unidade Responsável pela Gestão Orçamentária e Financeira (UGEOF) demonstrou que tantos as iniciativas sob gestão da Administração Central quanto aquelas sob gestão dos Departamentos incorrem em condições semelhantes de baixo desempenho da execução financeira dos convênios (Tabela 6).

Os resultados sinalizam que, possivelmente, as dificuldades enfrentadas na gestão dos convênios vinculados à administração central universitária e dos descentralizados, sob a gestão dos departamentos, são análogas, repercutindo em dimensão semelhante nos diferentes espaços de gestão universitária.

Tabela 6 - Unidade Gestora responsável pela execução orçamentária e financeira (UGEOF)

\begin{tabular}{l|c|c|c}
\hline \multirow{2}{*}{ UGEOF } & \multicolumn{2}{|c|}{ Execução Orçamentária/Financeira } & Total \\
\cline { 2 - 4 } & Execução Satisfatória & Execução Não Satisfatória & \\
\hline Administração Central & $5(9,4 \%)$ & $14(26,4 \%)$ & $19(35,8 \%)$ \\
\hline Departamento/Outros & $14(26,4 \%)$ & $20(37,7 \%)$ & $34(64,2 \%)$ \\
\hline Total & $19(35,8 \%)$ & $34(64,2 \%)$ & $53(100,0 \%)$ \\
\hline \hline
\end{tabular}

Fonte: Elaboração da pesquisa (OLIVEIRA, 2017).

A variável Vigência dos Convênios (VG) demonstrou que, dentre os 53 convênios celebrados pela instituição junto a instâncias federais, 17 (dezessete) $(32,1 \%$ ) tiveram vigência de até 2 anos, outros 17 (dezessete) (32,1\%) tiveram vigência superior a 2 anos e até 3 anos e 19 (dezenove) tiveram vigência superior a 3 anos (Tabela 7).

Importante salientar que a vigência é fixada de acordo com os prazos previstos para a consecução do objeto e em função das metas estabelecidas nos projetos, e que existe a obrigação de prorrogação de ofício da vigência do instrumento antes do seu término, quando a concedente dá causa a atraso na liberação dos recursos, limitada a prorrogação ao exato período do atraso verificado (BRASIL, 2011). 
Tabela 7 - Variável Vigência dos Convênios (VG)

\begin{tabular}{c|c|c|c}
\hline \multirow{2}{*}{ VG } & \multicolumn{2}{|c|}{ Execução Orçamentária/Financeira } & \multirow{2}{*}{ Total } \\
\cline { 2 - 4 } & Execução Satisfatória & Execução Não Satisfatória & \\
\hline Até 2 anos & $5(9,4 \%)$ & $12(22,6 \%)$ & $17(32,1 \%)$ \\
\hline De 2 até 3 anos & $6(11,3 \%)$ & $11(20,8 \%)$ & $17(32,1 \%)$ \\
\hline Acima de 3 anos & $8(15,1 \%)$ & $11(20,8 \%)$ & $19(35,8 \%)$ \\
\hline Total & $19(35,8 \%)$ & $34(64,2 \%)$ & $53(100,0 \%)$ \\
\hline \hline
\end{tabular}

Fonte: Elaboração da pesquisa (OLIVEIRA, 2017).

Os resultados obtidos na perspectiva da Vigência dos Convênios parecem sinalizar que o período de vigência dos instrumentos não repercute, de forma geral, no desempenho da execução financeira, visto que o desempenho dos convênios, em termos percentuais, com execução financeira insatisfatória e satisfatória são semelhantes.

Com o auxílio do software estatístico Statistical Package for the Social Sciences (SPSS), passou-se ao processo de estimação do modelo multivariado baseado na técnica da análise logística. A aplicação do método stepwise, procedimento estatístico que seleciona as variáveis com maior significância estatística e poder preditivo de solução ao fenômeno investigado, identificou o seguinte modelo matemático para a amostra investigada:

$$
\text { Modelo } \mathrm{Z}=-1,398+1,8382 \mathrm{X}_{4}+7,1999 \mathrm{X}_{3}-1,1487 \mathrm{X}_{5}
$$

Em que:

1,398 = intercepto da função;

$\mathrm{X}_{4}=$ abrangência do convênio (ABRAN) - dimensão espacial;

$\mathrm{X}_{3}=$ ação orçamentária (AORC) - dimensão acadêmica;

$\mathrm{X}_{5}=$ unidade institucional responsável pela gestão do convênio (UIRGC) - dimensão espacial.

Tabela 8 - Consolidação de Resultados dos Coeficientes

\begin{tabular}{l|l|l|l|l}
\hline Coeficientes & Estimativa & Erro padrão & Estatística Z & -valor \\
\hline Intercepto & $-1,398$ & 0,8127 & $-1,722$ & 0,0850 \\
\hline ABRAN [T.Inter/Comunid Ext] & $\mathbf{1 , 8 3 8 2}$ & 0,9176 & 2,003 & $\mathbf{0 , 0 4 5 1}$ \\
\hline AORC [T.Pesquisa] & $\mathbf{2 , 0 3 9 9}$ & 1,2921 & 1,579 & $\mathbf{0 , 1 1 4 4}$ \\
\hline AORC [T.Extensão] & $\mathbf{1 , 0 1 3 9}$ & 0,8169 & 1,241 & $\mathbf{0 , 2 1 4 5}$ \\
\hline AORC [T.Infraestrutura] & $\mathbf{4 , 1 4 6 1}$ & 1,6536 & 2,507 & $\mathbf{0 , 0 1 2 2}$ \\
\hline UIRGC [T.Departamento] & $\mathbf{- 1 , 4 9 8 7}$ & 1,0483 & $-1,430$ & $\mathbf{0 , 1 5 2 8}$ \\
\hline \hline
\end{tabular}

Fonte: Elaboração da pesquisa (OLIVEIRA, 2017).

O modelo matemático apresentado segrega as variáveis que têm maior grau de significância estatística para o estudo, as quais podem ser observadas na coluna p valor. Quando esse indicador está próximo a zero, indica-se que as variáveis têm significância estatística para o fenômeno estudado, neste caso, os fatores relevantes à execução de convênios celebrados com instâncias federais pela UNEB no período de 2009 a 2014 (Tabela 8). 
Nesse sentido, o modelo selecionou, dentre as 7 (sete) variáveis escolhidas para o estudo, aquelas que apresentaram maior significância para explicar o fenômeno da execução satisfatória ou não satisfatória dos convênios. Nesse sentido, indicou 3 (três) variáveis: Abrangência do Convênio (ABRAN), se departamental o interdepartamental, Ação Orçamentária (AORC), relacionada ao objeto do convênio, se ensino, pesquisa, extensão ou infraestrutura, e Unidade Responsável pela Gestão do Convênio (UIRGC), se Administração Central ou Unidades Departamentais (Tabela 8).

Dentre essas 03 (três) variáveis, o modelo matemático indicou que a Unidade Institucional, responsável pela gestão do convênio, é uma variável que impacta de forma negativa para o alcance de um percentual favorável de execução, tanto quando centralizada na Administração Central como quando descentralizada nos Departamentos.

Os resultados do modelo multivariado, possivelmente, sinalizam que uma possível distância entre o lócus da ação e a Administração Central - seja por questões normativas, administrativas e processuais talvez não equacionadas no âmbito da gestão descentralizada acaba repercutindo no cenário geral da execução orçamentária/financeira dos convênios.

De outro modo, ao não inserir as variáveis organizacionais no modelo, os resultados, possivelmente, sinalizam que o fato de contar com relativa robustez das práticas, métodos e estratégias enunciados pelos agentes federais de fomento parecem não constituir em entraves objetivos a execução financeira dos convênios firmados.

Outrossim, ao admitir aspectos da ação orçamentária, na constituição do modelo multivariado, possivelmente, sinalizam que as diferentes abordagens adotadas para os processos de execução financeira nas atividades de ensino, pesquisa, extensão e infraestrutura, repercutem, de forma mais significativa, no nível de execução orçamentária/financeira dos convênios (Tabela 8).

Quanto ao tempo de vigência dos convênios, assim como na abordagem descritiva, o modelo multivariado não selecionou essa variável, indicando, possivelmente, que os prazos celebrados nos instrumentos não repercutem de forma significativa em sua execução financeira.

A medida $x$-squared de 0.63196 indica que a abordagem estatística pela metodologia de regressão logística é adequada para responder ao fenômeno estudado, pois esse percentual precisa estar superior 0.50. O p-value de 0.7291 está um pouco elevado, pois, para esse indicador, o ideal é estar próximo a zero. Apesar de alguma limitação que esse percentual possa apresentar, não descaracteriza o modelo face o suporte dos resultados convergentes com a estatística descritiva (Tabela 8). 
De forma geral, a abordagem estatística na perspectiva da regressão logística resultou em robustez e parcimônia para a análise do fenômeno proposto no estudo, enriquecendo os resultados obtidos nas inferências descritivas e exploratórias.

A análise dos pesos dos fatores das variáveis indica que o êxito da execução dos convênios celebrados com instâncias federais pela UNEB no período de 2009 a 2014 está positivamente influenciado na categoria da Abrangência do Convênio, se departamental ou interdepartamental, da Ação Orçamentária dos objetos relacionados ao ensino, pesquisa, extensão e infraestrutura, que parecem demandar diferentes esforços e complexidades para sua execução, e, por fim, influenciada pela natureza centralizada ou descentralizada da unidade responsável pela gestão dos convênios dessas iniciativas, que, apesar de apresentar desempenhos percentuais semelhantes na análise descritiva, foi selecionado no modelo multivariado com influência negativa no desempenho geral (Tabela 8).

De outro modo, pode-se afirmar que, para a amostra investigada, as dimensões acadêmica e espacial são mais relevantes na execução financeira dos convênios celebrados pela UNEB que em relação à dimensão organizacional para a compreensão específica do fenômeno da gestão de convênios federais.

\section{Considerações finais}

Os resultados obtidos evidenciaram, no período estudado, um desempenho insatisfatório em execução orçamentária/financeira dos convênios celebrados pela UNEB no período de 2009 a 2014 com instâncias federais em torno de 65\%, consequentemente, um desempenho satisfatório de apenas $35 \%$ dos convênios celebrados.

O fato de se manter na base de dados os convênios para os quais não houve repasse de recursos, com o objetivo de se obter um diagnóstico mais amplo do desempenho desse instrumento de financiamento da atividade universitária, proporcionou perceber que os convênios provenientes de emendas parlamentares são aqueles que têm o maior índice de recursos não repassados, representando aproximadamente $13 \%$ dos $65 \%$ identificados para a variável dependente execução insatisfatória.

Os resultados obtidos identificaram a correlação positiva com as dimensões acadêmicas e espaciais referentes às seguintes variáveis independentes: Abrangência do Convênio (ABRAN), se departamental o interdepartamental, Ação Orçamentária (AORC), relacionada ao objeto do convênio, se ensino, pesquisa, extensão ou infraestrutura, e negativa para Unidade 
Responsável pela Gestão do Convênio (UIRGC), se Administração Central ou Unidades Departamentais.

Por fim, considerando a abrangência e relevância dessa universidade, enquanto agente de desenvolvimento no estado da Bahia, na perspectiva de oferta de atividade universitária (ensino, pesquisa e extensão), especialmente no interior do estado, da discussão salutar de estratégias de financiamento para manutenção de suas atividades, face os processos de restrições orçamentárias que vivenciam no contexto do Tesouro estadual e da omissão histórica de oferta federal de educação superior no interior do estado baiano, é salutar que a gestão universitária envide todos os esforços necessários para tornar mais eficaz a gestão de transferências voluntárias recebidas por meio de convênios, superando as possíveis especificidades de seu arranjo multicampi em sua configuração espacial.

Os resultados apresentados limitam-se à análise da delimitação histórica utilizada, da instituição objeto de estudo, e das técnicas metodológicas aplicadas, nesse sentido, indica-se a realização de novos estudos ampliando-se o período histórico analisado, utilização de outras instituições e outras fontes de financiamento, como estratégias capazes de contribuir para a ampliação do conhecimento no campo da gestão universitária, com ênfase no campo das instituições públicas não federais de educação superior (IPES) em seu movimento de identificação de instrumentos e fontes complementares de financiamento.

\section{Referências}

AMARAL, N. C. A educação superior brasileira: dilemas, desafios e comparações com os países da OCDE e do BRICS. Rev. Bras. Educ., São Paulo, v. 21, n. 66, p. 717-736, jul.-set. 2016. Disponível em: https://doi.org/10.1590/S1413-24782016216637. Acesso em: 14 ago. 2021.

AMARAL, N. C. Autonomia e financiamento das IFES: desafios e ações. Avaliação (Campinas; Sorocaba), Campinas, SP, v. 13, n. 3 p. 647-680, nov. 2008. Disponível em: https://doi.org/10.1590/S1414-40772008000300003. Acesso em: 14 ago. 2021.

BAHIA. Constituição (1989). Constituição do Estado da Bahia. Texto promulgado em 05 de outubro de 1989 e atualizado até a Emenda Constitucional nº 26, de 31 de janeiro de 2020. Salvador: Assembleia Legislativa, 05 out. 1989. Disponível em: http://www2.senado.leg.br/bdsf/handle/id/70433. Acesso em: 14 out. 2015.

BAHIA. Decreto Governamental $n^{\circ}$. 13.664/2012. Homologa o Recredenciamento da Universidade do Estado da Bahia, pelo CEE-Ba, período 2012-2020 e as alterações do Estatuto e Regimento Geral da UNEB. Diário Oficial do Estado da Bahia, Salvador, 8 fev. 2012, Seção, 1, p. 1-38. Disponível em: http://www.uneb.br/files/2009/10/Estatuto-UNEB2012.pdf. Acesso em: 8 dez. 2016. 
BAHIA. Decreto Governamental n. 9.751/2006. Homologa o Recredenciamento da UNEB, pelo CEE-Ba, período 2006-2010. Diário Oficial do Estado da Bahia, Salvador, 02 jan. 2006, Seção 1, p. 2.

BAHIA. Lei Delegada nº. 66/1983. Cria a Universidade do Estado da Bahia e dá outras providências. Diário Oficial do Estado da Bahia, Salvador, 2 jun. 1983, Seção 1, p. 21-22.

BAHIA. Lei Estadual nº 13.466 de 22 de dezembro de 2015. Dispõe sobre a organização e funcionamento das Universidades Estaduais da Bahia, revoga a Lei nº 7.176 de 10 de setembro de 1997 e dá outras providências. Diário Oficial do Estado da Bahia, Salvador, 23 dez. 2015. Disponível em: http://dovirtual.ba.gov.br/egba/reader2/. Acesso em: 15 jan. 2016.

BAHIA. Lei Estadual nº 7.176/1997. Reorganiza as instituições de ensino superior do Estado e dá outras providências. Diário Oficial do Estado da Bahia, Salvador, 11 set. 1997, Seção, 1, p. 10-13.

BAHIA. Portaria $n^{\circ}$. 1020/2008. Suspende a celebração de convênios, contratos ou atos congêneres entre a UNEB e as Fundações de Direito Privado, sem fins lucrativos, diretamente ou sob a modalidade de interveniência. Diário Oficial do Estado da Bahia, Salvador, 6 maio 2008, ano XCII, n. 19.690, Seção 1, p. 12.

BAHIA. Secretaria do Planejamento. Manual de orçamento público 2009. Salvador: Seplan, 2009. Disponível em: http://www.seplan.ba.gov.br/arquivos/File/manual-de-orcamentopublico/Ano2011/AnexoXII_versao_2011_1.pdf. Acesso em: 14 out. 2015.

BARBOSA, C. Financiamento Público das Universidades Estaduais Baianas: restrições orçamentárias, expansão universitária e desenvolvimento local. 2013. 165 f. Tese (Doutorado em Educação) - Programa de Pós-Graduação em Educação e Contemporaneidade, Departamento de Educação, Universidade do Estado da Bahia, Salvador, 2013. Disponível em: http://www.cdi.Uneb.br/pdfs/teses/2013/1109141328.pdf. Acesso em: 02 fev. 2016.

BOAVENTURA, E. M. A construção da universidade baiana: objetivos, missões e afrodescendência. Salvador: EDUFBA, 2009. SciELO Books. Disponível em: https://static.scielo.org/scielobooks/4r/pdf/boaventura-9788523208936.pdf. Acesso em: 27 abr. 2021.

BRASIL. Constituição (1998). Constituição da República Federativa do Brasil. Brasília, DF: Senado Federal, 1988.

http://www.planalto.gov.br/ccivil_03/Constituicao/Constituicao.htm.Disponível em: http://www.planalto.gov.br/ccivil_03/Constituicao/Constituicao.htm. Acesso em: 28 abr. 2015.

BRASIL. Decreto n. 6.170, de 25 de julho de 2007. Dispõe sobre as normas relativas às transferências de recursos da União mediante convênios e contratos de repasse, e dá outras providências. Diário Oficial [da] República Federativa do Brasil, Brasília, DF, 26 jul. 2007, Seção 1, p. 1.

BRASIL. Lei Complementar $\mathrm{n}^{\circ}$. 101, de 4 de maio de 2000. Lei de Responsabilidade Fiscal. Estabelece normas de finanças públicas voltadas para a responsabilidade na gestão fiscal e dá 
outras providências. Diário Oficial [da] República Federativa do Brasil, Brasília, DF, 05 maio 2000, Seção 1, p. 1.

BRASIL. Ministério da Educação e Cultura. Portaria Ministerial nº 909, de 31 de junho de 1995. Reconhece a Universidade do Estado da Bahia (UNEB), e dá outras providências.

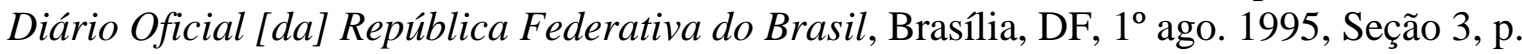
112.

BRASIL. Ministério do Planejamento, Desenvolvimento e Gestão. Portal de Convênios. Brasília: MPDG, 2016. Disponível em: http://www.convenios.gov.br. Acesso em: 23 jan. 2016.

BRASIL. Portaria Interministerial $\mathrm{n}^{\circ}$. 507, de 24 de novembro de 2011. Estabelece normas para execução do disposto no Decreto $n^{\circ}$. 6.170, de 25 de julho de 2007, que dispõe sobre as normas relativas às transferências de recursos da União mediante convênios e contratos de repasse, revoga a Portaria Interministerial no. 127/MP/MF/CGU, de 29 de maio de 2008 e dá outras providências. Diário Oficial [da] República Federativa do Brasil. Brasília, DF, 28 ago. 2011. Disponível em: http://portal.convenios.gov.br/legislacao/portarias/portariainterministerial-n-507-de-24-de-novembro-de-2011. Acesso em: 28 abr. 2015.

BRASIL. Portaria Interministerial $\mathrm{n}^{\mathrm{o}}$. 424, de 30 de dezembro de 2016. Estabelece normas para execução do estabelecido no Decreto $n^{\circ}$. 6.170, de 25 de julho de 2007, que dispõe sobre as normas relativas às transferências de recursos da União mediante convênios e contratos de repasse, revoga a Portaria Interministerial no. 507/MP/MF/CGU, de 24 de novembro de 2011 e dá outras providências. Diário Oficial [da] República Federativa do Brasil. Brasília, DF, 30 dez. 2016. Disponível em: http://portal.convenios.gov.br/legislacao/portarias/portariainterministerial-n-424-de-30-de-dezembro-de-2016. Acesso em: 12 maio. 2017.

BRASIL. Tribunal de Contas da União (TCU). Cartilha Convênios e outros repasses. 5. ed. Brasília, DF: TCU, 2014. Disponível em: http://portal.tcu.gov.br/biblioteca-digital/conveniose-outros-repasses.htm. Acesso em: 01 ago. 2015.

CARVALHO, C. H. A. O PROUNI no governo Lula e o jogo político em torno do acesso ao ensino superior. Educ. Soc., São Paulo, v. 27, n. 96. p. 979-1000, out. 2006. Disponível em: https://doi.org/10.1590/S0101-73302006000300016.

CHAVES, V. L. J.; AMARAL, N. C. Política de Expansão da Educação Superior no Brasil O Prouni e o Fies como financiadores do setor privado. Educ. rev., Belo Horizonte, v. 32, n. 4 p. 49-72, out.-dez. 2016. Disponível em: https://doi.org/10.1590/0102-4698162030. Acesso em: 14 ago. 2021.

CONCEIÇÃO, S. H.; PEREIRA, A. F. O. A. Estudo do Desempenho Econômico Financeiro das Emissoras de Televisão Aberta do Brasil. In: CONGRESSO BRASILEIRO DE CUSTOS, 13., 2006, Belo Horizonte. Anais... São Leopoldo: Associação Brasileira de Custos, 2006. Disponível em: https://anaiscbc.emnuvens.com.br/anais/article/view/1832/1832. Acesso em: 30 set. 2019.

CORBUCCI, P. R. Financiamento e democratização do acesso à educação superior no Brasil: da deserção do Estado ao projeto de reforma. Educ. Soc., São Paulo, v. 25, n. 88. p. 677-701, 
out. 2004. Disponível em: https://doi.org/10.1590/S0101-73302004000300003Acesso em: 14 ago. 2021.

CUNHA, L. A. Desenvolvimento desigual e combinado no ensino superior: Estado e mercado. Educ. Soc., São Paulo, v. 25, n. 88. p. 795-817, out. 2004. Disponível em: https://doi.org/10.1590/S0101-73302004000300008. Acesso em: 14 ago. 2021.

DONOSO, D. S. Políticas e instrumentos de financiación de estudios universitarios: encrucijadas para el diseño de sistemas de financiamiento sustentables. Ensaio: aval. pol. públ. Educ., São Paulo, v. 16, n. 60. p. 359-392, set. 2008. Disponível em: https://doi.org/10.1590/S0104-40362008000300004. Acesso em: 14 ago. 2021.

FARENZENA, N. A assistência financeira da União às políticas educacionais locais. Revista Retratos da Escola, Brasília, v.6, n.10, p.105-117, 2008. Disponível em: http://www.esforce.org.br/index.php/semestral/article/view/173/330. Acesso em: 23 jan. 2016.

FIALHO, N. H. Universidade Multicampi. Brasília, DF: Plano Editora, 2005.

HAIR JR., J. F. et al. Fundamentos de Métodos de Pesquisa em Administração. Tradução Lene Belon Ribeiro. Porto Alegre: Bookman, 2005.

LIMA, K. R. S. O Banco Mundial e a educação superior brasileira na primeira década do novo século. Rev. Katálysis, Florianópolis, v. 14, n. 1. p. 86-94, jun. 2011. Disponível em: https://doi.org/10.1590/S1414-49802011000100010. Acesso em: 14 ago. 2021.

MOTA, W. P. O Banco Mundial e a contrarreforma da educação superior brasileira no governo Lula da Silva (2003-2010). Avaliação (Campinas), Campinas, SP, v. 24, n. 1, p. $213-$ 233, mar.-maio 2019. Disponível em: https://doi.org/10.1590/S1414-407720190001000012. Acesso em: 14 ago. 2021.

MOTA JÚNIOR, A.; CONCEIÇÃO, S. H. Dimensões Relevantes à Política de Financiamento do Sistema Educação Superior do Estado da Bahia. Práticas em Gestão Pública Universitária, Rio de Janeiro, ano 4, v. 4, n. 1, p. 99-124, jan.-jun. 2020. Disponível em: https://revistas.ufrj.br/index.php/pgpu/article/view/34314/20004. Acesso em: 27 abr. 2021.

OLIVEIRA, C. N. Fontes complementares de financiamento em Universidades Públicas: análise sobre a Gestão de Convênios Federais em uma Universidade Estadual, Multicampi e Multirregional. 2017. 96 f. Relatório Técnico (Mestrado) - Mestrado Profissional em Gestão e Tecnologias Aplicadas à Educação (GESTEC), Universidade do Estado da Bahia (UNEB), Salvador, 2017.

SANTOS, A. V.; CHAVES, V. L. J. Influência de atores privados no fortalecimento da privatização da educação superior brasileira. Educ. Soc., São Paulo, v. 41, 2020. Disponível em: https://doi.org/10.1590/ES.241276. Acesso em: 14 ago. 2021.

SEGRERA, F. L. Educación Superior Comparada: Tendencias Mundiales y de América Latina y Caribe. Avaliação (Campinas), Campinas, SP, v. 21, n. 1. p. 13-32, mar. 2016. 
Disponível em: https://doi.org/10.1590/S1414-40772016000100002. Acesso em: 14 ago. 2021.

SILVA, E. G. A expansão da Universidade Federal do Amazonas: implicações a partir do financiamento em tempos de crise. Avaliação (Campinas), Campinas, SP, v. 24, n. 1. p. 2644, mar.-maio 2019. Disponível em: https://doi.org/10.1590/S1414-40772019000100003. Acesso em: 14 ago. 2021.

SGUISSARDI, V. Universidade pública estatal: entre o público e privado/mercantil. Educ. Soc., São Paulo, v. 26, n. 90. p. 191-222, abr. 2005. Disponível em: https://doi.org/10.1590/S0101-73302005000100009. Acesso em: 14 ago. 2021.

TRINDADE, H. A República em tempos de reforma universitária: o desafio do Governo Lula. Educ. Soc., São Paulo, v. 25, n. 88. p. 819-844, out. 2004. Disponível em: https://doi.org/10.1590/S0101-73302004000300009. Acesso em: 14 ago. 2021.

UNIVERSIDADE DO ESTADO DA BAHIA (UNEB). Plano de Desenvolvimento Institucional (PDI) - 2013-2017. Salvador: Uneb/Proplan, 2013. Disponível em: http://www.Uneb.br/proplan/files/2013/07/PDI-2017_WEB.pdf. Acesso em: 01 ago. 2016.

UNIVERSIDADE DO ESTADO DA BAHIA (UNEB). Regimento Geral da UNEB.

Salvador: Eduneb, 2012. Disponível em: http://www.uneb.br/files/2009/10/REGIMENTOGERAL-DA-UNEB-2012.pdf. Acesso em: 8 dez. 2016.

VELLOSO, J. Universidade na América Latina: rumos do financiamento. Cad. Pesqui., São Paulo, n. 110, p. 39-66, jul. 2000. Disponível em:

http://www.scielo.br/pdf/cp/n110/n110a02.pdf. Acesso em: 10 ago. 2015.

VELLOSO, J.; MARQUES, P. M. F. Recursos próprios da UNB, o financiamento das IFES e a reforma da educação superior. Educ. Soc., São Paulo, v. 26, n. 91. p. 655-680, ago. 2005. Disponível em: https://doi.org/10.1590/S0101-73302005000200018. Acesso em: 14 ago. 2021. 